\title{
Effects of DX-9065a, an Inhibitor of Factor Xa, on Ellagic Acid-Induced Plantar Skin Thrombosis Assessed in Tetrodotoxin- and $N^{\omega}$-Nitro-L- Arginine-Treated Rats
}

\author{
Daisuke Chino $^{\# 1}$, Yukiyoshi Fujita, Kunio Ishii\# ${ }^{\# 2}$ and Koichi Nakayama* \\ Department of Pharmacology, Faculty of Pharmaceutical Sciences, University of Shizuoka, \\ 52-1 Yada, Shizuoka 422-8526, Japan
}

Received April 8, 2002; Accepted February 13, 2003

\begin{abstract}
Effects of DX-9065a ((+)-2S-2-[4-[[(3S)-1-acetimidoyl-3-pyrrolidinyl]oxy]phenyl]-3[7-amidino-2-naphthyl]propanoic acid hydrochloride pentahydrate), a dibasic propanoic acid and an inhibitor of factor Xa, were compared with those of argatroban, a low molecular weight thrombin inhibitor, on the ellagic acid-induced plantar skin thrombosis in the rats treated with tetrodotoxin and $N^{\omega}$-nitro-L-arginine. Plantar skin blood flow was measured with laser Doppler flow meters, and skin temperature of the hindlimb was monitored simultaneously. In order to induce thrombus in plantar skin vasculature, ellagic acid (300 $\mu$ g, i.a.) was injected into a branch of femoral artery. The formation of thrombus in femoral and plantar vessels was assessed by light microscopy. Ellagic acid decreased plantar skin blood flow and skin temperature. Intravenous injections of DX-9065a $(3 \mathrm{mg} / \mathrm{kg})$ and argatroban $(1-3 \mathrm{mg} / \mathrm{kg})$ significantly inhibited the ellagic acid-induced disturbance of plantar skin blood flow and lowering skin temperature without affecting bleeding time. The oral administration of DX-9065a $(30-100 \mathrm{mg} / \mathrm{kg})$ significantly prevented the decrease in skin temperature induced by ellagic acid, but it partially inhibited the disturbance of plantar skin blood flow. DX-9065a and argatroban also prolonged prothrombin time in a dose-dependent manner. These results suggest that DX-9065a effectively prevented thrombosis produced by ellagic acid in the skin circulation without a risk of bleeding.
\end{abstract}

Keywords: DX-9065a, ellagic acid, skin blood flow, thrombosis, tetrodotoxin- and $N^{\omega}$-nitro-L-arginine-treated rat

\section{Introduction}

DX-9065a $((+)-2 S-2-[4-[[(3 S)-1-a c e t i m i d o y l-3-p y r r o-$ lidinyl]oxy]phenyl]-3-[7-amidino-2-naphthyl]propanoic acid hydrochloride pentahydrate), dibasic propanoic acid, is a selective inhibitor of factor Xa $(1,2)$ and has been reported to be an orally active anticoagulant $(3-5)$. DX-9065a exhibited anticoagulant activity in various animal models of thrombosis, such as thromboplastininduced disseminated intravascular coagulation in the

\footnotetext{
*Corresponding author. FAX: +81-54-264-5696

E-mail: nakyamk@ys7.u-shizuoka-ken.ac.jp

Present address:

${ }^{\# 1}$ Department of Physiology and Biochemistry, School of Nursing, Chiba University, Chiba 260-8670, Japan

${ }^{\# 2}$ Department of Molecular Pharmacology, Faculty of Pharmaceutical Sciences, Kitasato University, Tokyo 108-8641, Japan
}

rat $(4,6,7)$, mouse, and rabbit (5), or arterial-venous $(\mathrm{A}-\mathrm{V})$ shunt in the rat $(4,8,9)$. The clinical trial of this drug in humans at phase I was recently conducted (10).

In the present study, in order to further elucidate the potential action of DX-9065a to improve disturbed skin circulation, we established ellagic acid-induced thrombosis in the plantar skin area of the rat hindlimb.

We previously reported the preparation of acutelydenervated rats (11) by the combined treatments with tetrodotoxin (TTX), a $\mathrm{Na}^{+}$channel inhibitor, and $N^{\omega}$ nitro-L-arginine (L-NNA), a NO synthetase inhibitor. TTX is known to acutely denervate nervous elements involved in efferent and afferent reflex mechanisms (12). L-NNA (13), administered via the i.v. route, could induce a pressor response (14), and thus it can counteract the lowered systemic blood pressure and peripheral 
vascular tone following elimination of sympathetic nerve activity.

Ellagic acid is known to be one of the most efficient initiators of blood coagulation by conversion of Hageman factor to an active serine protease (15). Consequently, intraarterial injection of ellagic acid into a branch of a femoral artery can produce locally an ischemic change in the plantar skin of one hindlimb, while the other hindlimb can serve as the control. This experimental model enabled us to properly compare the effects of DX-9065a with those of argatroban on the disturbed skin blood flow in the rats. Our results suggest that DX-9065a effectively prevented ellagic acid-induced disturbance of plantar skin blood flow (PSBF) and the decrease in skin temperature (ST) without affecting the bleeding time.

\section{Materials and Methods}

The present study was reviewed by the ethics committee on animal experiments at the University of Shizuoka and was carried out in accordance with the institutional guidelines for animal experiments, the Guiding Principles for the Care and Use of Laboratory Animals approved by The Japanese Pharmacological Society, and the law (No. 105) and notification (No. 6) of care and protection of animals established by the Japanese Government.

\section{Preparation of TTX-and L-NNA-treated rat}

Male Wistar rats, 9-13-week-old and weighing $250-320 \mathrm{~g}$ (Japan SLC, Hamamatsu), were lightly anesthetized with diethyl ether. After disappearance of the corneal reflex, each animal was placed on a heating mat. After tracheotomy, the trachea was intubated and the animal was ventilated with room air $(1 \mathrm{ml} / 100 \mathrm{~g}$ body weight) with an artificial respirator (SN-480-7; Shinano Seisakusyo, Tokyo) operating at 85 strokes/min. The left jugular vein was cannulated for the intravenous injection of drugs and sampling of blood serum. The right carotid artery was cannulated for recording arterial blood pressure (TDN-R; Gould, Oxnard, CA, USA) and heart rate (HR) triggered by the pulse of blood pressure signal. These outputs were fed into a Macintosh computer set at an input of $10 \mathrm{~V}$ via an analog-digital signal converter (LAB STAC; Keisokugiken, Tokyo). A side branch of a femoral artery was cannulated for the intraarterial injection of ellagic acid. In order to eliminate nervous activity totally, TTX $(50 \mu \mathrm{g} / \mathrm{kg}$, i.v. $)$ was injected. Afterwards, L-NNA ( $30 \mathrm{mg} / \mathrm{kg}$, i.v.) was injected to counteract (for about $2 \mathrm{~h}$ ) the low blood pressure due to the TTX-induced loss of vascular tone. We previously reported that TTX (50 $\mu \mathrm{g} / \mathrm{kg}$, i.v.) could totally inhibit the pressor response to electrical stimulation of the spinal cord, and the reflex tachycardia due to the depressor response to acetylcholine (1 $\mu \mathrm{g} / \mathrm{kg}$, i.v. ) (11). Room temperature was controlled at $24 \pm 1^{\circ} \mathrm{C}$ with a humidity of $55 \pm 1 \%$, and the body temperature of the animal was maintained at $36 \pm 0.5^{\circ} \mathrm{C}$ by a rectal thermistor probe linked to a temperature controller of the heating mat.

\section{Measurements of plantar skin blood flow and skin temperature}

The PSBFs of both hindlimbs were continuously measured with laser Doppler flow meters (FLO-N1; Omega Wave Co., Ltd., Tokyo) with a time constant of $1 \mathrm{~s}$. Each flow probe was held at a $2.5-\mathrm{mm}$ distance from the skin surface of the plantar area of each hindlimb. The two blood flow signals were fed into a Macintosh computer via an analog-digital signal converter. The blood flow was expressed as milliliter per minute per $100 \mathrm{~g}$ tissue weight or percent change of the value before drug administration. The vascular resistance $\left(\mathrm{mmHg} 100 \mathrm{~g} \cdot \mathrm{min} \cdot \mathrm{ml}^{-1}\right)$ was calculated as the mean blood pressure (MBP) (mmHg) divided by the PSBF $\left(\mathrm{ml} \cdot \mathrm{min}^{-1} \cdot 100 \mathrm{~g}^{-1}\right)$. The skin temperature (ST) at each dorsum pedis was measured with a sticker type temperature indicator (ProChecker; Kyowa Medics Co., Ltd., Tokyo).

To disturb PSBF by causing thrombosis, we intraarterially injected ellagic acid $(300 \mu \mathrm{g})$, which had been suspended in the rat serum prepared according to the method previously reported by Hara et al. (16), into a side branch of one of the femoral arteries.

In order to evaluate the effectiveness of drug action via two different routes of drug administration on the ellagic acid-induced disturbance of PSBF, we adopted the following experimental protocols, as depicted in Fig. 1.

In the intravenous administration study, the drug (DX-9065a or argatroban) or vehicle was injected into a jugular vein $20 \mathrm{~min}$ after the injection of TTX $(50 \mu \mathrm{g}$ $/ \mathrm{kg}$, i.v.) and L-NNA (30 mg $/ \mathrm{kg}$, i.v.). DX-9065a (0.3$3.0 \mathrm{mg} / \mathrm{kg}$ ) was injected over a 15 -s period, whereas argatroban $(0.3-3.0 \mathrm{mg} / \mathrm{kg})$ was injected in 15 to $60 \mathrm{~s}$, depending on its injection volume. The effects of drugs per se on HR, MBP, PSBF, and ST were observed for $15 \mathrm{~min}$. Afterwards, ellagic acid, suspended in rat serum $(3.0 \mathrm{mg} / \mathrm{ml})$ in a volume of $100 \mu \mathrm{l}$, was injected into a side branch of a femoral artery, and the effects of drugs on the PSBF as well as other parameters (ST, HR, and MBP) were observed for $60 \mathrm{~min}$.

In the oral administration study, the rats were fasted overnight. DX-9065a (30-100 mg/kg) or vehicle was administered via a gastric tube $30 \mathrm{~min}$ prior to admin- 


\section{A. Intravenous injection study}

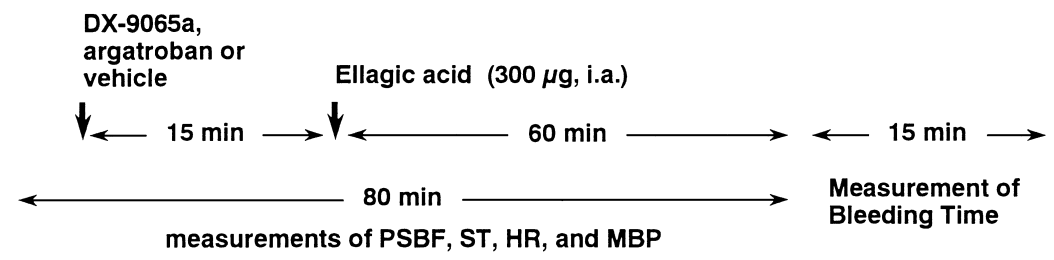

\section{B. Oral administration study}

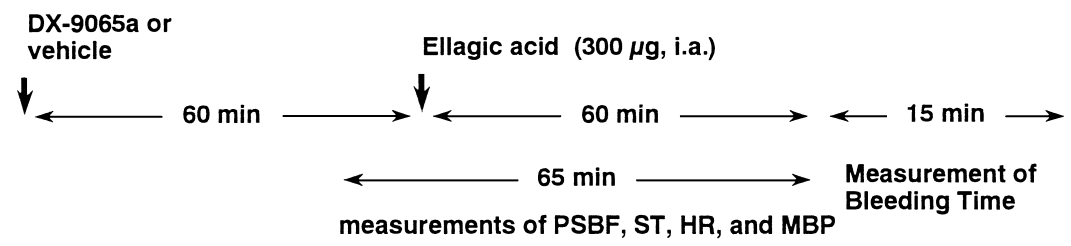

Fig. 1. Schematic diagrams of experimental protocols. Perpendicular arrows indicate the treatment with drugs or vehicle. PSBF, ST, HR, and MBP represent plantar skin blood flow, skin temperature, heart rate, and mean blood pressure, respectively.

istration of TTX $(50 \mu \mathrm{g} / \mathrm{kg}, \mathrm{i} . \mathrm{v}$.$) and L-NNA (30 mg$ $/ \mathrm{kg}$, i.v.). Ellagic acid was injected into a side branch of a femoral artery $60 \mathrm{~min}$ after administration of the drug, and the effect of the drug on the PSBF was observed for about $1 \mathrm{~h}$.

Since the PSBF reduced less than $2.0 \mathrm{ml} \cdot \mathrm{min}^{-1}$. $100 \mathrm{~g}^{-1}$ when the femoral artery was completely occluded with a clip, we considered that the blood flow of the plantar skin area was completely occluded when the PSBF decreased less than $2.0 \mathrm{ml} \cdot \mathrm{min}^{-1} \cdot 100 \mathrm{~g}^{-1}$. Thus, the total duration of complete occlusion time was estimated.

\section{Measurements of prothrombin time and bleeding time}

In the intravenous injection study, the blood sample $(270 \mu \mathrm{l})$ was collected $15 \mathrm{~min}$ after injection of DX9065a or argatroban from the jugular vein of each rat in a $1-\mathrm{ml}$ syringe containing $30 \mu \mathrm{l}$ of $3.1 \%$ trisodium citrate dihydrate. In the oral administration study, the blood sample $(270 \mu \mathrm{l})$ was collected from the jugular vein $60 \mathrm{~min}$ after the administration of DX-9065a. Blood samples were centrifuged at $1,500 \times \mathrm{g}$ for $10 \mathrm{~min}$ at $4^{\circ} \mathrm{C}$, and platelet-poor plasma was stored at $-20^{\circ} \mathrm{C}$ until assayed. Frozen plasma was thawed at $37^{\circ} \mathrm{C}$ and placed in a crushed-ice bath. Plasma $(20 \mu 1)$ was placed in the process tube, and the coagulation was started by addition of Simplastin (Sankyo, Tokyo) (40 $\mu 1)$. After that, prothrombin time (PT) was measured with a Microcoagulometer (Greiner Electronics AG, Langenthal, Switzerland).
Bleeding time was determined by transection of the rat tail at the end of experiments, as shown in Fig. 1. After the intravenous injection and oral administration of drugs for 75 and 120 min, respectively, bleeding was induced by transection of the extremity of the tail $3 \mathrm{~mm}$ from the tip. A drop of blood from the tail was gently blotted with tissue paper every $15 \mathrm{~s}$, and the time to cessation of bleeding was noted. To avoid bleeding again, we took care not to touch the cut area of the tail. If the bleeding time was prolonged over $15 \mathrm{~min}$, the value was taken as $15 \mathrm{~min}$.

\section{Histological study}

In order to ascertain whether thrombus formation in vivo was induced by ellagic acid or not, we did a histological study. Male Wistar rats, 9-10-week-old and weighing $250-300 \mathrm{~g}$, were prepared as described above; $30 \mathrm{~min}$ after the injection of ellagic acid (300 $\mu$ g, i.a.), which actually disturbed PSBF, the rats were killed by exsanguination and perfused transcardially for $1 \mathrm{~min}$ with saline (total volume of about $20 \mathrm{ml}$ ). Both hindlimbs were immediately removed and fixed overnight in 10\% formaldehyde. Plantar and femoral sections were cut into 5 - $\mu$ m-thick sections by use of a microtome, and then each section was stained with hematoxylin and eosin (HE), elastica-van Gieson stain, or phosphotungstic acid hematoxylin (PTAH) for evaluation by light microscopy. 


\section{Materials}

The following drugs were used: DX-905a, Slonnon injection (argatroban) and ellagic acid dihydrate were gifts from Daiichi (Tokyo). TTX was purchased from Wako (Osaka), and L-NNA from Aldrich (Milwaukee, WI, USA). Other drugs of reagent grade were commercially available. Slonnon injection $(20 \mathrm{ml})$ contained argatroban (10 mg), and D-sorbitol (1.08 g) as a additive. In the case of intravenous injection of argatroban $(3.0 \mathrm{ml} / \mathrm{kg})$, the drug was dissolved in distilled water to a concentration of $1.2 \mathrm{mg} / \mathrm{ml}$, because the Slonnon injection volume was too much for a bolus injection. LNNA was dissolved in $0.1 \mathrm{~N} \mathrm{HCl}$ to a concentration of $10 \mathrm{mg} / \mathrm{ml}$. Other drugs were dissolved in physiologic salt solution. The injection volume of each drug was $50 \mu \mathrm{l} / 100 \mathrm{~g}$ body weight except for that of argatroban and L-NNA.

\section{Statistical analyses}

The data were expressed as the mean \pm S.E.M. Evaluation of the statistical significance among groups was carried out by Dunnett's multiple comparison test after analysis of variance (ANOVA). A $P$ value of less than 0.05 was considered significant.

\section{Results}

Ellagic acid-induced thrombosis of plantar skin area in TTX-and L-NNA-treated rats

To determine the appropriate dose of ellagic acid to disturb the PSBF in TTX- and L-NNA-treated rats, we performed preliminary experiments in which the drug was injected up to $300 \mu \mathrm{g}$ into a branch of the left femoral artery. Ellagic acid decreased PSBF dosedependently, and $\mathrm{ID}_{50 \% \mathrm{PSBF}}$, i.e., the dose required to decrease PSBF up to $50 \%$ of the basal value, was $99.1 \pm 5.3 \mu$ g, i.a. $(\mathrm{n}=4)$.

Hemodynamic variables before and after intravenous injection of TTX $(50 \mu \mathrm{g} / \mathrm{kg})$ and subsequent injection of L-NNA $(30 \mathrm{mg} / \mathrm{kg})$ in rats $(\mathrm{n}=4)$ are given in Table 1 . TTX significantly decreased the HR, MBP, and vascular resistance to PSBF. However, the lowered MBP and vascular resistance to PSBF were restored by the subsequent injection of L-NNA to almost the same level as those before the injection of TTX. Thus, the PSBF was not largely affected. The intravenous injection of L-NNA was effective in counteracting the lowered MBP by TTX for more than $2 \mathrm{~h}$ (data not shown).

Figure 2A shows the typical responses of PSBF to intraarterial injection of ellagic acid $(300 \mu \mathrm{g})$. Apparently, ellagic acid interrupted PSBF in a variety of ways; i.e., PSBF fluctuated from one minute to the next, as shown in panel A of Fig. 2. However, the summarized data indicated that a bolus injection of ellagic acid (300 $\mu$ g, i.a.) inhibited PSBF of the injected side very severely to about $20 \%$ of the the basal blood flow for an observation period of $60 \mathrm{~min}$, whereas the contralateral PSBF remained constant (Fig. 2B). Intraarterial injection of ellagic acid had no apparent effect on HR and MBP (data not shown).

Histological surveys confirmed the formation of thrombi. Figure 3 shows light microscopic observations of femoral blood vessels and those in the plantar skin area excised from the injected hindlimb $30 \mathrm{~min}$ after the injection of ellagic acid $(300 \mu \mathrm{g} / \mathrm{kg}$, i.a.) and stained with HE or elastica-van Gieson stain. The contralateral hindlimb served as the control.

The vessel lumens of the ellagic acid-injected side were packed with thrombi. The fibrin deposits in the thrombi were confirmed when the vessels were stained with phosphotungstic acid hematoxylin. To the contrary, there was no thrombus formation in the contralateral vessels. These results suggest that the disturbance of PSBF by ellagic acid can be attributed to the formation of thrombus in femoral blood vessels and those in the plantar skin area.

Antithrombotic effects of DX-9065a and argatroban administered intravenously on the ellagic acid-induced plantar skin thrombosis

The PSBF and ST of the left hindlimb and the HR and MBP before the intraarterial injection of ellagic acid

Table 1. Hemodynamic variables before and after intravenous injection of TTX and subsequent injection of L-NNA in rats anesthetized with diethyl ether

\begin{tabular}{lccc}
\hline & Before & $\begin{array}{c}\text { After TTX } \\
(50 \mu \mathrm{g} / \mathrm{kg}, \text { i.v. })\end{array}$ & $\begin{array}{c}\text { After TTX }(50 \mu \mathrm{g} / \mathrm{kg}, \text { i.v. }) \\
\text { and L-NNA }(30 \mathrm{mg} / \mathrm{kg}, \text { i.v. })\end{array}$ \\
\hline HR (beats/min) & $433 \pm 14$ & $345 \pm 9^{* *}$ & $349 \pm 9^{* *}$ \\
MBP $(\mathrm{mmHg})$ & $145 \pm 4$ & $69 \pm 3 * *$ & $147 \pm 4$ \\
PSBF $\left(\mathrm{ml} \cdot \mathrm{min}^{-1} \cdot 100 \mathrm{~g}^{-1}\right)$ & $10.5 \pm 0.6$ & $10.7 \pm 0.2$ & $10.8 \pm 0.40$ \\
Resistance to PSBF $\left(\mathrm{mmHg} 100 \mathrm{~g} \cdot \mathrm{min} \cdot \mathrm{ml}^{-1}\right)$ & $13.9 \pm 0.4$ & $6.5 \pm 0.2^{* *}$ & $13.6 \pm 0.1$ \\
\hline
\end{tabular}

Each value represents the mean \pm S.E.M. of the same 4 animals. L-NNA was administered 15 min after injection of TTX. ${ }^{*} P<0.01$ vs corresponding values before injection of TTX. 
A

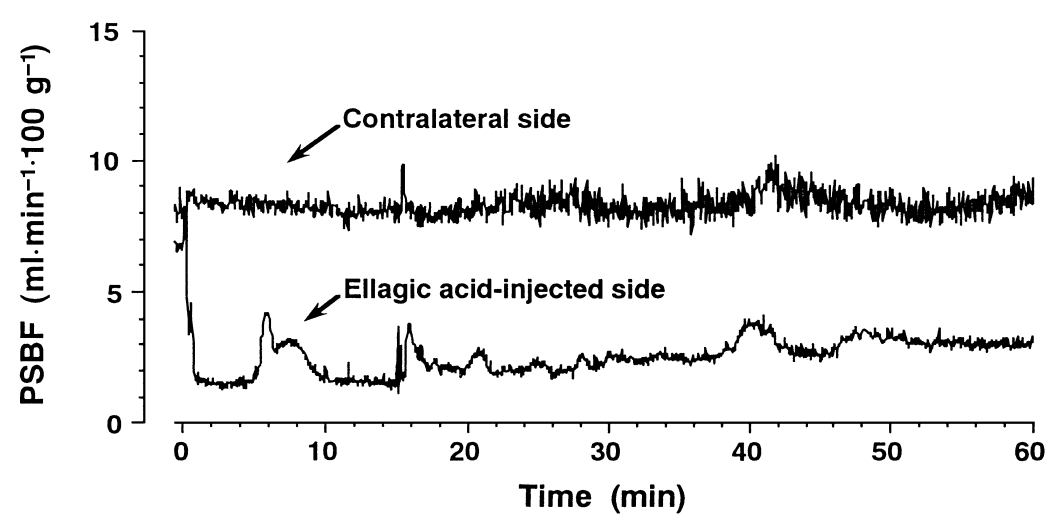

B

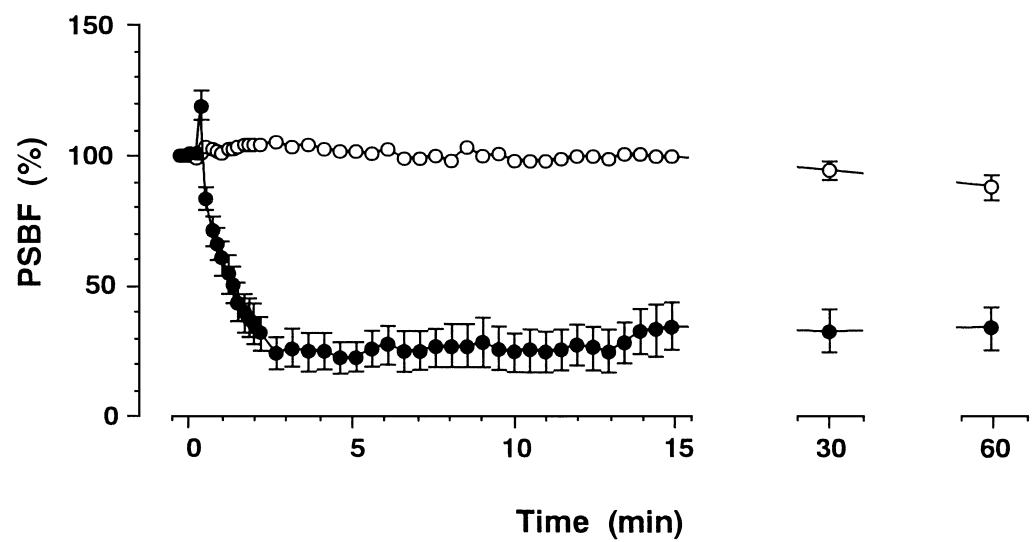

Fig. 2. Effects of ellagic acid on the plantar skin blood flow (PSBF) in tetrodotoxin (TTX)- and $N^{\omega}$-nitro-L-arginine (L-NNA)treated rats. Panel A shows typical responses of PSBF to ellagic acid (300 $\mu$ g, i.a.) taken from the control group. Ellagic acid $(300 \mu \mathrm{g})$ was injected into a branch of the left femoral artery in each animal. Panel B: Time-courses of changes in PSBF. PSBF of ellagic acid-injected side (closed circles) and that of the contralateral side (open circles) were simultaneously measured. Ellagic acid $(300 \mu \mathrm{g})$ was injected intra-arterially at time zero. Each point with a vertical bar represents the mean \pm S.E.M. of 14 experiments. Each value before injection of ellagic acid was taken as $100 \%$ on the ordinate.

in the total number of rats used in the present series of experiments $(\mathrm{n}=60)$ were $11.0 \pm 0.3 \mathrm{ml} \cdot \mathrm{min}^{-1} \cdot 100 \mathrm{~g}^{-1}$, $32.5 \pm 0.2^{\circ} \mathrm{C}, \quad 340 \pm 4$ beats $/ \mathrm{min}$, and $128 \pm 3 \mathrm{mmHg}$, respectively. These control values among the groups were not significantly different (each $n=7-14$ ).

The preventive effects of either DX-9065a or argatroban pretreatment for $60 \mathrm{~min}$ on the maximum ellagic acid (300 $\mu$ g, i.a.)-induced changes in PSBF and ST of the ipsilateral hindlimb were shown in Fig. 4. In the vehicle-treated rats, ellagic acid ( $300 \mu$ g, i.a.) decreased PSBF to about $20 \%$ of the basal value in about $2 \mathrm{~min}$ (Fig. 2B). Consistent with the disturbed PSBF, the ST of the hindlimb on the ellagic acid-injected side was lowered to $-4.9 \pm 0.4^{\circ} \mathrm{C}$ from the control $\left(32.6 \pm 0.2^{\circ} \mathrm{C}\right)$ (each $\mathrm{n}=14$ ). The intravenous administration of DX9065a or argatroban significantly and dose-dependently inhibited the disturbance of PSBF and the decrease in ST induced by ellagic acid. In the control group, the total duration of complete occlusion time was $35.1 \pm$ $7.0 \mathrm{~min}(\mathrm{n}=14)$. DX-9065a at 1 and $3 \mathrm{mg} / \mathrm{kg}$ reduced it to $13.7 \pm 9.2 \mathrm{~min}(\mathrm{n}=7)$ and $6.4 \pm 5.8 \mathrm{~min}(\mathrm{n}=9)$ $(P<0.05$ vs corresponding vehicle), respectively. Argatroban at $1 \mathrm{mg} / \mathrm{kg}$ also reduced the total duration of complete occlusion time to $15 \pm 9.8 \min (\mathrm{n}=8)$, and the drug at $3 \mathrm{mg} / \mathrm{kg}$ abolished the occurrence of complete occlusion, $(\mathrm{n}=8)(P<0.01$ vs corresponding vehicle).

Effects of the oral administration of DX-9065a on the ellagic acid-induced plantar skin thrombosis

The PSBF and ST of the left hindlimb and the HR and MBP before the intraarterial injection of ellagic acid were $10.0 \pm 0.4 \mathrm{ml} \cdot \mathrm{min}^{-1} \cdot 100 \mathrm{~g}^{-1}, 31.8 \pm 0.3^{\circ} \mathrm{C}$, 


\section{Ellagic acid-injected side A Plantar}

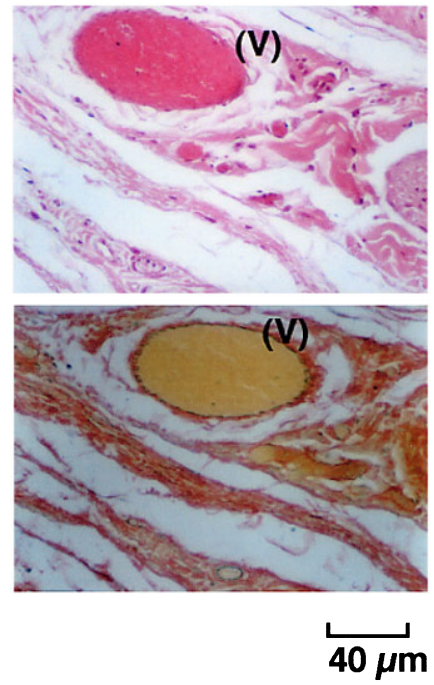

\section{B Femoral}
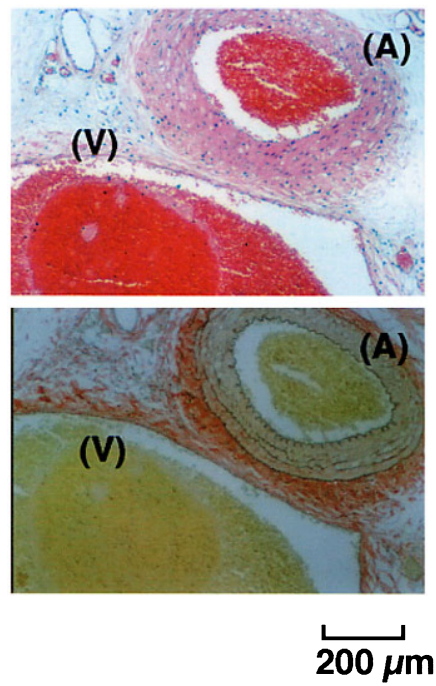

\section{Contralateral side C Plantar}
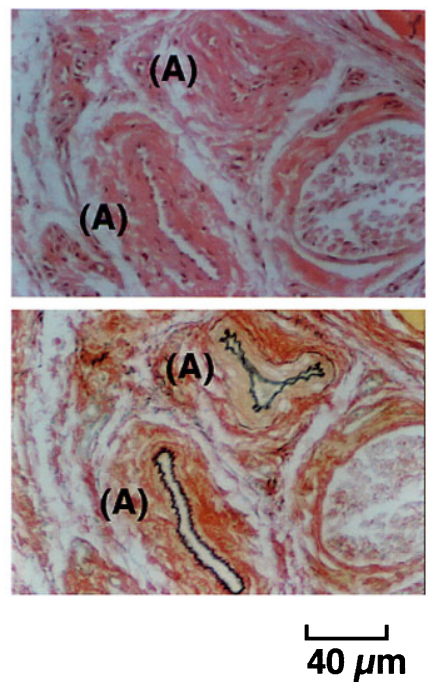

\section{Femoral}
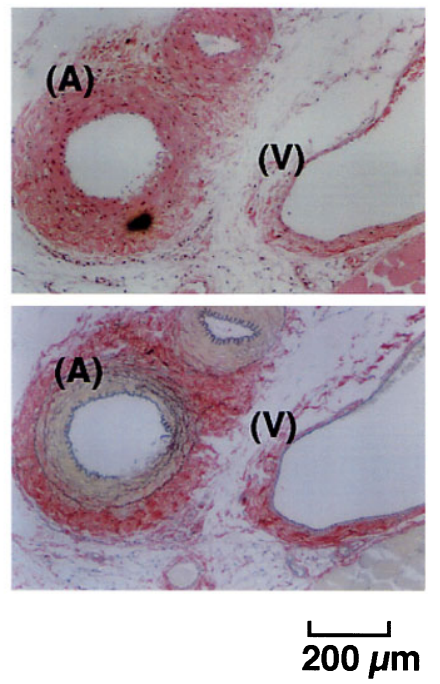

Fig. 3. Light microscopic views of transected plantar (panels A and C) and femoral (panels B and D) vessels which had been excised $30 \mathrm{~min}$ after injection of ellagic acid (300 $\mu \mathrm{g}$, i.a.) into a branch of femoral artery in tetrodotoxin (TTX)- and $N^{\omega}$-nitro-Larginine (L-NNA)-treated rats. Panels A and B show the preparations of ellagic acid-injected side. Panels C and D show the preparations of the contralateral side. Each upper panel shows the preparation stained with hematoxylin and eosin (HE). Each lower panel shows the preparation stained with elastica-van Gieson stain. Note that the venous lumens are evidently occluded by thrombi. (A) and (V) represent artery and vein, respectively.

$353 \pm 7$ beats $/ \mathrm{min}$, and $107 \pm 5 \mathrm{mmHg}$, respectively (total animals, $\mathrm{n}=22$ ). These basal values were not significantly different among the vehicle- and drugtreated groups (each $n=6-9$ ).

In the vehicle-treated group, ellagic acid ( $300 \mu$ g, i.a.) induced the disturbance of PSBF and the decrease of ST. The oral administration of DX-9065a (30 and $100 \mathrm{mg} / \mathrm{kg}$ ) tended to inhibit the disturbance of PSBF, and significantly prevented the decrease in ST induced by ellagic acid $(P<0.01$, Fig. 4D), but it partially inhibited the disturbance of PSBF. In the control group, the total duration of complete occlusion time was $36.9 \pm$ $10 \mathrm{~min}(\mathrm{n}=7)$. DX-9065a at $30 \mathrm{mg} / \mathrm{kg}$ and $100 \mathrm{mg} / \mathrm{kg}$ tended to reduce it to $11.9 \pm 8.4 \min (\mathrm{n}=6)$ and $11.8 \pm$ $6.7 \min (n=9)$, respectively. 


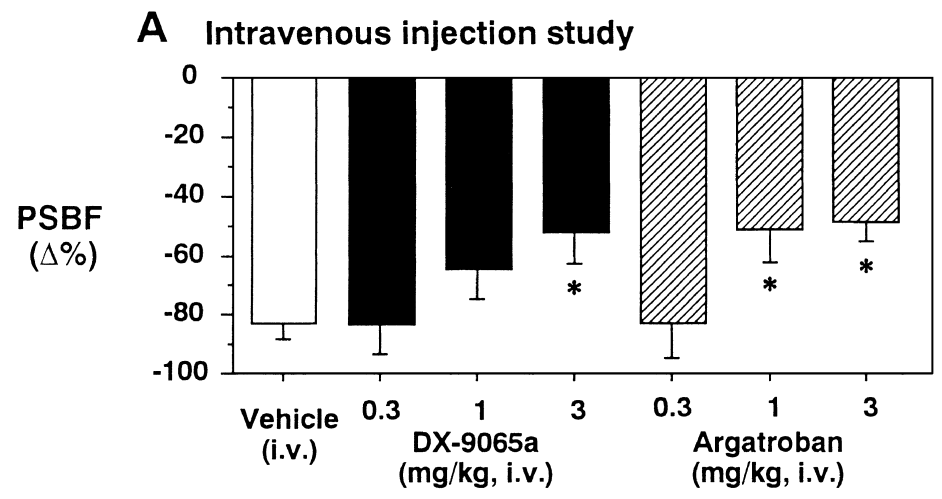

\section{Intravenous injection study}

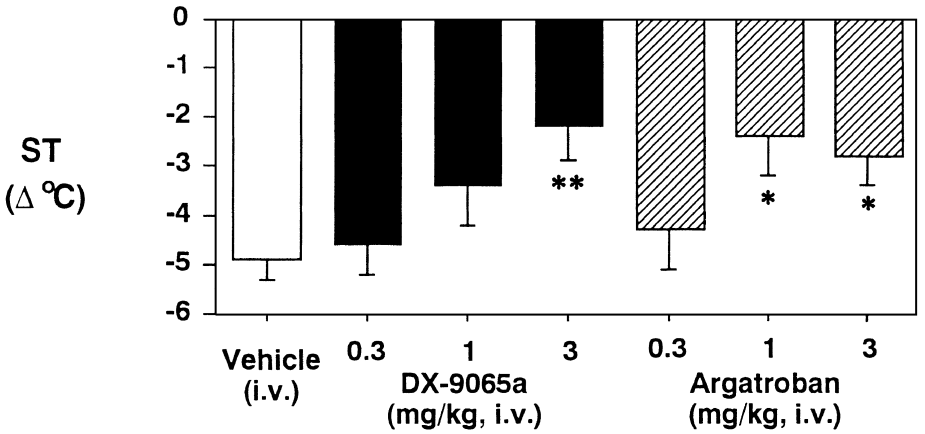

B Oral administration study

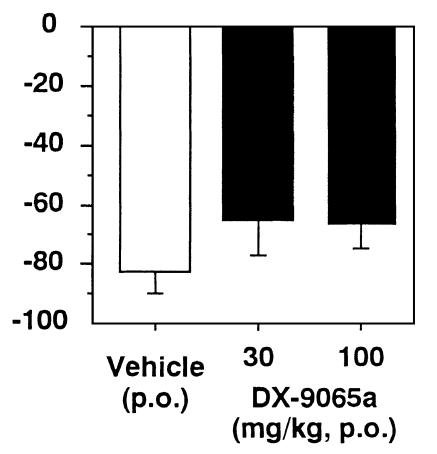

D Oral administration study

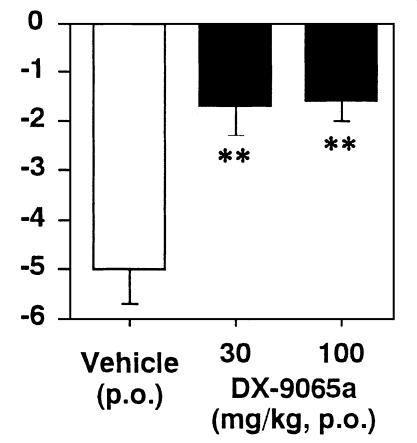

Fig. 4. Effects of DX-9065a and argatroban on the maximum ellagic acid (300 $\mu$ g, i.a.)-induced changes in plantar skin blood flow (PSBF) (panels A and B) and skin temperature (ST) (panels C and D) in tetrodotoxin (TTX)- and $N^{\omega}$-nitro-L-arginine (L-NNA)-treated rats. Panels A and C show the results of the intravenous injection study and panels B and D, those of the oral administration study. Each PSBF before injection of ellagic acid was taken as $100 \%$ on the ordinate. Each ST was expressed as $\Delta$ decrease from the control. Data represent the mean \pm S.E.M. of $7-14$ experiments. ${ }^{*} P<0.05, * * P<0.01$ vs corresponding value of vehicle.

Cardiovascular effects of DX-9065a and argatroban administered intravenously to TTX- and L-NNA-treated rats

The cardiovascular effects of the intravenous injection of the drugs (DX-9065a or argatroban) were evaluated before the injection of ellagic acid and are summarized in Table 2.

The HR, MBP, and PSBF before the intravenous injection of the drugs were $347 \pm 3$ beats $/ \mathrm{min}, 139 \pm$ $3 \mathrm{mmHg}$, and $11.0 \pm 0.2 \mathrm{ml} \cdot \mathrm{min}^{-1} \cdot 100 \mathrm{~g}^{-1}$, respectively (total animals, $n=60$ ). These values were not significantly different among the groups (each $n=7-14$ ).

Intravenous injection of DX-9065a did not affect the HR, MBP, and PSBF at any dose used. On the other hand, the intravenous injection of argatroban at a dose range between 1 and $3 \mathrm{mg} / \mathrm{kg}$ significantly increased MBP.
Effects of DX-9065a and argatroban on prothrombin time and bleeding time

The value of prothrombin time for the vehicle-treated group in the intravenous injection study was $18.6 \pm 1.1 \mathrm{~s}$ $(n=5)$. Intravenous injection of DX-9065a and argatroban prolonged prothrombin time in a dose-dependent manner. There was a significant prolongation of prothrombin time when DX-9065a (3 mg $/ \mathrm{kg})$ or argatroban $(3 \mathrm{mg} / \mathrm{kg}$ ) was administered (each $P<0.01$, vs corresponding vehicle) (Fig. 5A).

Prothrombin time in the vehicle-treated group of the oral administration study was $16.5 \pm 1.1 \mathrm{~s}(\mathrm{n}=8)$. Oral administration of DX-9065a also dose-dependently prolonged prothrombin time. A significant prolongation of prothrombin time was induced by DX-9065a at $100 \mathrm{mg} / \mathrm{kg}$, p.o. (Fig. 5B).

The effects of DX-9065a and argatroban on the bleeding time in TTX- and L-NNA-treated rats were also evaluated by the tail transection method (Fig. 5: C, D). Neither of these drugs had apparent effect on the bleeding time. 
Table 2. Effects of intravenous injection of DX-9065a and argatroban on heart rate (HR), mean blood pressure (MBP) and plantar skin blood flow (PSBF) in TTX-L-NNA-treated rats

\begin{tabular}{|c|c|c|c|c|c|c|c|}
\hline \multirow[b]{2}{*}{ Drug } & \multirow[b]{2}{*}{$\mathrm{n}$} & \multicolumn{3}{|c|}{ Control values (as 100\%) } & \multicolumn{3}{|c|}{ After drug treatment } \\
\hline & & $\begin{array}{c}\text { HR } \\
\text { (beats } / \mathrm{min} \text { ) }\end{array}$ & $\begin{array}{c}\text { MBP } \\
(\mathrm{mmHg})\end{array}$ & $\begin{array}{c}\text { PSBF } \\
\left(\mathrm{ml} \cdot \mathrm{min}^{-1} \cdot 100 \mathrm{~g}^{-1}\right)\end{array}$ & $\mathrm{HR}(\%)$ & MBP (\%) & PSBF $(\%)$ \\
\hline Vehicle (saline) & 14 & $356 \pm 9$ & $141 \pm 5$ & $10.1 \pm 0.5$ & $100.7 \pm 0.3$ & $102.8 \pm 0.5$ & $107.4 \pm 0.9$ \\
\hline \multicolumn{8}{|l|}{ DX-9065a } \\
\hline $0.3 \mathrm{mg} / \mathrm{kg}$ & 7 & $355 \pm 7$ & $153 \pm 7$ & $11.9 \pm 0.9$ & $100.8 \pm 0.3$ & $102.2 \pm 0.6$ & $106.8 \pm 1.4$ \\
\hline $1.0 \mathrm{mg} / \mathrm{kg}$ & 7 & $342 \pm 8$ & $139 \pm 7$ & $10.1 \pm 0.4$ & $100.4 \pm 0.3$ & $103.8 \pm 0.4$ & $104.1 \pm 1.2$ \\
\hline $3.0 \mathrm{mg} / \mathrm{kg}$ & 9 & $348 \pm 6$ & $139 \pm 9$ & $11.9 \pm 0.5$ & $100.2 \pm 0.1$ & $104.4 \pm 1.4$ & $105.0 \pm 1.3$ \\
\hline \multicolumn{8}{|l|}{ Argatroban } \\
\hline $0.3 \mathrm{mg} / \mathrm{kg}$ & 7 & $338 \pm 10$ & $133 \pm 8$ & $11.8 \pm 0.6$ & $100.3 \pm 0.2$ & $105.2 \pm 1.0$ & $103.5 \pm 0.2$ \\
\hline $1.0 \mathrm{mg} / \mathrm{kg}$ & 8 & $345 \pm 8$ & $138 \pm 7$ & $11.2 \pm 0.9$ & $100.3 \pm 0.2$ & $107.8 \pm 0.9 *$ & $109.0 \pm 2.1$ \\
\hline $3.0 \mathrm{mg} / \mathrm{kg}$ & 8 & $334 \pm 11$ & $130 \pm 4$ & $10.7 \pm 0.5$ & $100.6 \pm 0.4$ & $111.7 \pm 2.3 * *$ & $108.8 \pm 1.4$ \\
\hline
\end{tabular}

Control values were measured before drug treatments. The maximal change in response is expressed as $\%$ of the control value $(=100 \%)$. Each value represents the mean \pm S.E.M. of number of experiments $(\mathrm{n})$. ${ }^{*} P<0.05, * * P<0.01$ vs corresponding value of vehicle.

A Intravenous injection study

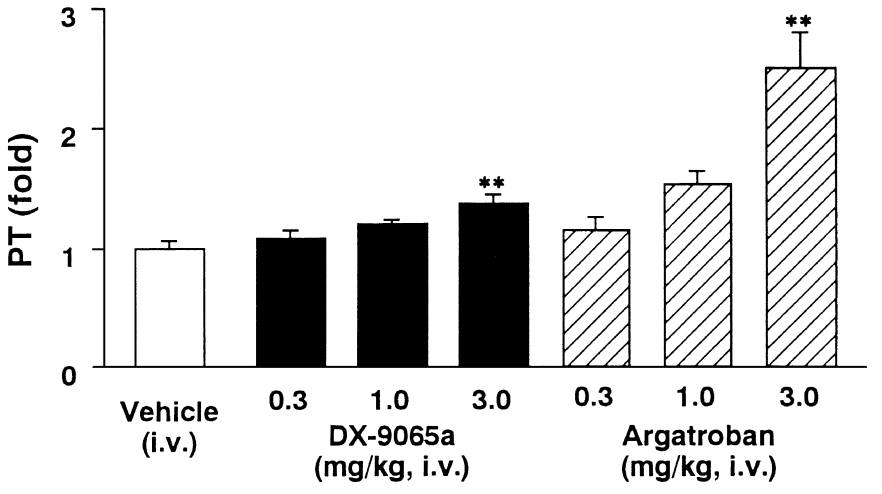

C Intravenous injection study

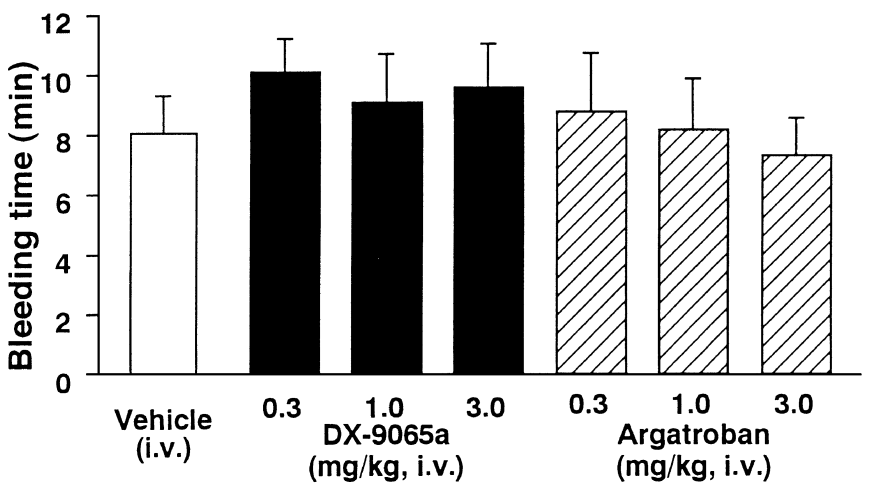

B Oral administration study

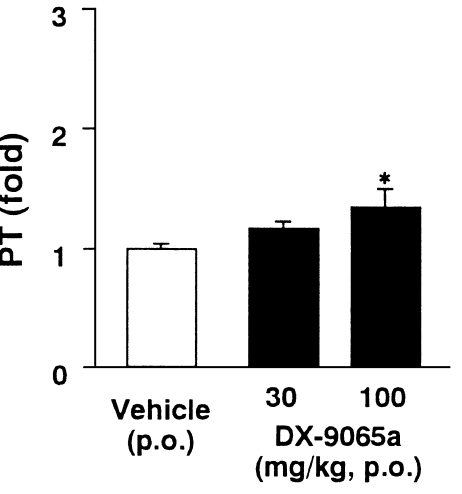

D Oral administration study

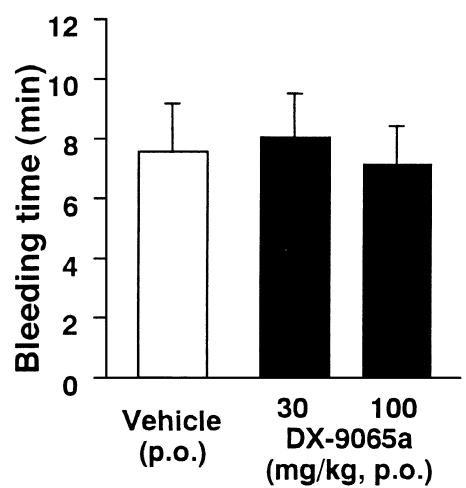

Fig. 5. Effects of DX-9065a and argatroban on prothrombin time (PT) (panels A and B) and bleeding time (panels C and D) in tetrodotoxin (TTX)- and $N^{\omega}$-nitro-L-arginine (L-NNA)-treated rats. Panels A and C show the results of the intravenous injection study and panels B and D, those of the oral administration study. Each PT was normalized to the mean value of the vehicle-treated group. Bleeding time was determined at the end of each experiment; i.e., 75 min after the intravenous injection of each drug and $120 \mathrm{~min}$ after oral administration of DX-9065a. Data represent the mean \pm S.E.M. of $5-14$ experiments. $* P<0.05, * * P<0.01$ vs corresponding value of vehicle. 


\section{Discussion}

The present study demonstrated that the intravenous and oral administrations of DX-9065a, an inhibitor of factor Xa, effectively attenuated the disturbance in PSBF by ellagic acid in TTX- and L-NNA-treated rats, which was possibly due to thrombus formation and erythrocyte aggregation in the plantar and/or femoral vasculature, whereas the drug did not affect the bleeding time.

Ellagic acid is known to be one of the most efficient initiators of blood coagulation by converting Hageman factor to an active serine protease (15). There are several reports on ellagic acid-induced thrombosis in various animal models for evaluation of antithrombotic effects of drugs $(16-19)$. However, in these experimental models, prior to local injection of ellagic acid into the femoral artery in rats (17) and rabbits (19) or into the cerebral arteries via the carotid artery in rats (16), a ligature or clipping of the arteries was necessary to locally induce thrombus and the subsequent disturbance of blood flow.

In the present study, the intraarterial injection of ellagic acid $(300 \mu \mathrm{g})$ into a branch of a femoral artery could induce the disturbance of PSBF without any additional procedures, such as the ligation of a femoral artery. It was previously reported that a NO synthase inhibitor, such as $N^{\omega}$-nitro-L-arginine methyl ester (LNAME), increased the volume of the thrombus induced by iontophoretic application of adenosine diphosphate (ADP) into the lumen of mesenteric venules of rats (20). Since endothelium-derived relaxing factor (EDRF)/NO inhibits thrombus growth (20), it could be highly probable that the L-NNA-treated rats were more susceptible to induction of thrombosis due to the reduced production of EDRF/NO by L-NNA.

Histologically, platelet-rich thrombi were observed in veins, and the aggregates of erythrocytes were recognized in arteries of the ellagic acid-injected hindlimb. These findings suggest that the thrombus formation and erythrocyte aggregation that occurred in the vascular regions of the femoral blood vessels and plantar skin area probably led to the disturbance in PSBF.

As neuronal reflex mechanisms are well developed in the cutaneous circulation (21), sympathetic efferents exert a strong influence on the skin blood flow (22). Here, we prepared acutely denervated rats by the combined use of TTX and L-NNA (11). TTX (50 $\mu \mathrm{g} / \mathrm{kg}$, i.v. $)$ could eliminate basal sympathetic nerve activity and inhibit excitation of sympathetic nerve through the reflex mechanisms including depressor responses. Although multiple pressor mechanisms of L-NNA, including inhibition of NO synthetase, have been reported
(14), a bolus injection of L-NNA (30 mg/kg, i.v.) apparently counteracted the lowered blood pressure and peripheral vascular tone that resulted from elimination of sympathetic nerve activity as well as inhibition of endothelium-derived relaxing factor (EDRF)/NO-induced vasodilation. This experimental model thus enabled us to observe direct actions of drugs on skin blood flow without neuronal interference (11).

Here, we chose argatroban as a control drug, because the drug showed a more potent antithrombotic action in comparison with a conventional coagulant such as heparin $(16,23-25)$. Argatroban has been used clinically in Japan since the early 1980's, and it was also recently approved for clinical use in the United States to treat with patients suffering from heparin-induced thrombocytopenia (26).

It has been reported that DX-9065a has a high selectivity as an inhibitor of factor $\mathrm{Xa}(\mathrm{Ki}=41 \mathrm{nM})$ and that its inhibitory activities toward thrombin and other serine proteases are very low $(\mathrm{Ki}=200 \mu \mathrm{M})(3)$. On the other hand, argatroban, a low-molecular-weight arginine derivative, selectively and directly inhibits thrombin (27). Our present study showed that the dosage of DX$9065 \mathrm{a}$ (3 mg/kg, i.v.) required to inhibit significantly the disturbance in PSBF by ellagic acid was comparable to that of argatroban $(1-3 \mathrm{mg} / \mathrm{kg}$, i.v.; Fig. 4). In addition, DX-9065a (3 mg/kg, i.v.) significantly prolonged prothrombin time to an extent similar to that observed with argatroban $(1 \mathrm{mg} / \mathrm{kg}, \mathrm{i} . \mathrm{v}$.$) .$

It has been reported that the plasma thrombinantithrombin III complex level was suppressed after the administration of argatroban in patients with peripheral arterial obstructive disease, along with the improvement of their clinical symptoms and a decrease in the size of ischemic skin ulcers (28). Taken together, the inhibition of factor Xa by DX-9065a seems to be an alternative therapeutic approach to treat peripheral thrombosis often encountered in peripheral arterial obstructive disease.

We showed that DX-9065a prolonged prothrombin time after intravenous or oral administration in a dosedependent manner, as previously reported by Hara et al. (3). The oral administration of DX-9065a inhibited significantly the decrease in ST. The drug attenuated the disturbance of PSBF, although not to a statistically significant extent (Fig. 4B). However, we noted that the ST decreased, depending on the time of disturbed PSBF. In the present study, the oral administration of DX-9065a tended to reduce the total duration of complete occlusion time. Therefore, the oral administration of DX-9065a inhibited significantly the decrease in ST without significant effect on the maximum inhibition of PSBF.

In our study, DX-9065a and argatroban did not pro- 
long the bleeding time. A selective factor Xa inhibitor, such as recombinant tick anticoagulant peptide and hirudin, hardly prolonged bleeding time in a canine thrombosis model (29). DX-9065a was also reported not to prolong bleeding time in rats $(4,7)$ or rabbits $(5)$. On the other hand, it was reported that the intravenous infusion of argatroban prolonged the bleeding time at the dose showing antithrombotic effects in guinea pigs (30). This discrepancy can be explained as follows: The plasma concentration of argatroban declines exponentially with an elimination half-life of about $20 \mathrm{~min}$ in humans (31), in whom it also has a short duration of action (32), as in rats (33). In present study, the measurements of bleeding time started at $75 \mathrm{~min}$ after the injection of the drugs (see Fig. 1), so that most of the argatroban in plasma would have been degraded. That would be a reason why no significant prolongation of bleeding time was observed in the argatroban-treated group. On the other hand, the half-life of DX-9065a after oral administration was $2.3 \mathrm{~h}$ in humans (34). It was reported that the activated partial thromboplastin time and prothrombin time were significantly prolonged at least for $2 \mathrm{~h}$ after intravenous injection and oral administration of DX-9065a in rats (3). Therefore, our data show that DX-9065a did not affect bleeding time in spite of sufficient plasma concentration to prolong both activated partial thromboplastin time and prothrombin time at 75 and 120 min after intravenous injection and oral administration, respectively.

In conclusion, both the intravenous injection and oral administration of DX-9065a showed inhibitory effects on the plantar skin thrombosis induced by the ellagic acid without the prolongation of bleeding time. Intravenous injection of argatroban presented almost the similar inhibitory effect on the disturbance of PSBF and decrease in ST in response to ellagic acid. Therefore, our study suggests that the inhibition of factor Xa by DX-9065a would be an alternative therapeutic approach to treat peripheral thrombosis occurring in the skin circulation without a risk of bleeding.

\section{Acknowledgments}

We thank Daiichi (Tokyo) for the gifts of DX-9065a and argatroban. The advice and suggestions by Profs. K. Hashimoto and M. Mitsumata, at the Yamanashi Medical University, and Drs. T. Ishikawa, Y. Tanabe, and K. Obara are highly appreciated as well. We also thank Misses A. Shirotake and M. Nakamura for their excellent technical assistance.

\section{References}

1 Nagahara T, Yokoyama Y, Inamura K, Katakura S, Komoriya S, Yamaguchi H, Hara T and Iwamoto M: Dibasic (amidinoaryl) propanoic acid derivatives as novel blood coagulation factor Xa inhibitors. J Med Chem 37, 1200 - 1207 (1994)

2 Hara T, Yokoyama A, Morishima Y and Kunitada S: Species differences in anticoagulant and anti-Xa activity of DX-9065a, a highly selective factor Xa inhibitor. Thromb Res 80, 99- 104 (1995)

3 Hara T, Yokoyama A, Ishihara H, Yokoyama Y, Nagahara T and Iwamoto M: DX-9065a, a new synthetic, potent anticoagulant and selective inhibitor for factor Xa. Thromb Haemost 71, 314 319 (1994)

4 Hara T, Yokoyama A, Tanabe K, Ishihara $\mathrm{H}$ and Iwamoto M: DX-9065a, an orally active, specific inhibitor of factor Xa, inhibits thrombosis without affecting bleeding time in rats. Thromb Haemost 74, 635 - 639 (1995)

5 Herbert JM, Bernat A, Dol F, Herault JP, Crepon B and Lormeau JC: DX 9065A a novel, synthetic, selective and orally active inhibitor of factor Xa: in vitro and in vivo studies. J Pharmacol Exp Ther 276, 1030 - 1038 (1996)

6 Yamazaki M, Asakura H, Aoshima K, Saito M, Jokaji H, Uotani C, Kumabashiri I, Morishita E, Ikeda T and Matsuda T: Effects of DX-9065a, an orally active, newly synthesized and specific inhibitor of factor $\mathrm{Xa}$, against experimental disseminated intravascular coagulation in rats. Thromb Haemost 72, 392-396 (1994)

7 Yamazaki M, Asakura H, Aoshima K, Saito M, Jokaji H, Uotani C, Kumabashiri I, Morishita E, Ikeda T and Matsuda T: Protective effects of DX-9065a, an orally active, novel synthesized and selective inhibitor of factor Xa, against thromboplastininduced experimental disseminated intravascular coagulation in rats. Semin Thromb Haemost 22, 255 - 259 (1996)

8 Wong PC, Crain EJ Jr, Nguan O, Watson CA and Racanelli A: Antithrombotic actions of selective inhibitors of blood coagulation factor $\mathrm{Xa}$ in rat models of thrombosis. Thromb Res 83, $117-126$ (1996)

9 Morishima Y, Tanabe K, Terada Y, Hara T and Kunitada S: Antithrombotic and hemorrhagic effects of DX-9065a, a direct and selective factor $\mathrm{Xa}$ inhibitor: comparison with a direct thrombin inhibitor and antithrombin III-dependent anticoagulants. Thromb Haemost 78, 1366 - 1371 (1997)

10 Porcari AR, Chi L and Leadley R: Recent advances in clinical trials of the direct and indirect selective Factor Xa inhibitors. Expert Opinion on Investigational Drugs 9, 1595 - 1600 (2000)

11 Chino D, Akimaru S, Kataha K, Ishii K and Nakayama K: Specific augmentation of plantar skin blood flow by lipo-PGE assessed in tetrodotoxin- and $N^{\mathrm{G}}$-nitro-L-arginine-treated rats. J Cardiovasc Pharmacol 35, 630 - 637 (2000)

12 Nunoki $\mathrm{K}$ and Iijima T: Modification of the baroreceptor reflex by superfusion of the canine posterior hypothalamus with tetrodotoxin. Naunyn Schmiedebergs Arch Pharmacol 321, $185-189$ (1982)

13 Ishii K, Chang B, Kerwin JF Jr, Huang ZJ and Murad F: $N^{\omega}$ Nitro-L-arginine: a potent inhibitor of endothelium-derived relaxing factor formation. Eur J Pharmacol 176, 219 - 223 (1990)

14 Nakahara T, Ishii K, Tanaka Y and Nakayama K: Involvement of neurohumoral factors in the pressor mechanism of $N^{\mathrm{G}}$-nitro-Larginine. Eur J Pharmacol 287, 49 - 56 (1995) 
15 Bock PE, Srinivasan KR and Shore JD: Activation of intrinsic blood coagulation by ellagic acid: insoluble ellagic acid-metal ion complexes are the activating species. Biochemistry 20, $7258-7266(1981)$

16 Hara T, Iwamoto $M$, Ishihara $M$ and Tomikawa M: Preventive effect of argatroban on ellagic acid-induced cerebral thromboembolism in rats. Haemostasis 24, $351-357$ (1994)

17 De Clerck F, Goossens J, Vermylen J, Hornstra G and Reneman RS: Modification of venous stasis thrombosis in the rat by platelet-active drugs and by heparin. Arch Int Pharmacodyn Ther 222, 233 - 242 (1976)

18 Suehiro A, Kakishita E and Nagai K: The role of platelet hyperfunction in thrombus formation inhyperlipidemia. Thromb Res 25, $331-339$ (1982)

19 Uzunova AD, Ramey ER and Ramwell PW: Gonadal hormones and pathogenesis of occlusive arterial thrombosis. Am J Physiol 234, H454 - H459 (1987)

20 Peire MA and Puig-Parellada P: Oxygen-free radicals and nitric oxide are involved in the thrombus growth produced by iontophoresis of ADP. Pharmacol Res 38, 353 - 356 (1998)

21 Johnson JM, Brengelmann GL, Hales JR, Vanhoutte PM and Wenger CB: Regulation of the cutaneous circulation. Fed Proc 45, $2841-2850$ (1986)

22 Cooke JP, Creager MA, Osmundson PJ and Shepherd JT: Sex differences in control of cutaneous blood flow. Circulation 82, 1607 - 1615 (1990)

23 Imura Y, Stassen JM and Collen D: Comparative antithrombotic effects of heparin, recombinant hirudin and argatroban in a hamster femoral vein platelet-rich mural thrombosis model. J Pharmacol Exp Ther 261, 895 - 898 (1992)

24 Kawai H, Yamamoto T, Hara H and Tamao Y: Inhibition of factor Xa-induced platelet aggregation by a selective thrombin inhibitor, argatroban. Thromb Res 74, 185 - 191 (1994)

25 Umemura K, Kawai H, Ishihara $\mathrm{H}$ and Nakashima M: Inhibitory effect of clopidogrel, vapiprost and argatroban on the middle cerebral artery thrombosis in the rat. Jpn J Pharmacol 67, 253 258 (1995)
26 Moledina M, Chakir M and Gandhi PJ: A synopsis of the clinical uses of argatroban. J Thromb Thrombolys 12, 141 - 149 (2001)

27 Okamoto S, Hijikata A, Kikumoto R, Tonomura S, Hara H, Ninomiya K, Maruyama A, Sugano M and Tamao Y: Potent inhibition of thrombin by the newly synthesized arginine derivative No. 805. The importance of stereo-structure of its hydrophobic carboxamide portion. Biochem Biophys Res Commun 101, 440 - 446 (1981)

28 Matsuo T, Kario K, Matsuda S, Yamaguchi N and Kakishita E: Effect of thrombin inhibition on patients with peripheral arterial obstructive disease: A Multicenter Clinical Trial of Argatroban. J Thromb Thrombolys 2, 131 - 136 (1995)

29 Sitko GR, Ramjit DR, Stabilito II, Lehman D, Lynch JJ and Vlasuk GP: Conjunctive enhancement of enzymatic thrombolysis and prevention of thrombotic reocclusion with the selective factor Xa inhibitor, tick anticoagulant peptide. Comparison to hirudin and heparin in a canine model of acute coronary artery thrombosis. Circulation 85, $805-815$ (1992)

30 Kawamura M, Imura Y, Moriya N, Kita S, Fukushi H, Sugihara H, Nishikawa K and Terashita Z: Antithrombotic effects of TAK-029, a novel GPIIb/IIIa antagonist, in guinea pigs: comparative studies with ticlopidine, clopidogrel, aspirin, prostaglandin $E_{1}$ and argatroban. J Pharmacol Exp Ther 277, 502 - 510 (1996)

31 Clarke RJ, Mayo G, Fitzgerald GA and Fitzgerald DJ: Combined administration of aspirin and a specific thrombin inhibitor in man [see comments]. Circulation 83, 1510 - 1518 (1991)

32 Verstraete M: Pharmacotherapeutic aspects of unfractionated and low molecular weight heparins. Drugs 40, 498 - 530 (1990)

33 Sasaki Y, Morii S, Yamashita T and Yamamoto J: Antithrombotic effect of argatroban on the pial vessels of the rat: a study with $\mathrm{He}-\mathrm{Ne}$ laser-induced thrombus formation. Haemostasis 23, $104-111$ (1993)

34 Murayama N, Tanaka S, Kikuchi T, Nakaoka M and Sudo K: Radioimmunoassay method for DX-9065a, an anticoagulant agent. Development, evaluation and application to human plasma. J Pharm Biomed Anal 14, 1435 - 1445 (1996) 